ISSN: 2146-3042

DOI: $10.25095 /$ mufad.579646

\title{
Denetim Kalitesinin Kar Yönetimi Üzerine Etkisi: Bist-100 Firmaları Üzerine Bir Uygulama
}

\author{
Aysel ÖZTÜRKÇÜ AKÇAY*
}

Abdulkadir BİLEN**

\section{$\ddot{O Z Z E T}$}

Bu çalışmanın temel amacı denetim kalitesi ve kar yönetimi arasındaki ilişkiyi incelemektir. Bu amacı gerçekleştirmek üzere 2009-2015 yıllarını kapsayan ve Borsa İstanbul BiST 100 endeksinde işlem gören farklı sektörlere ait firmaların yıllık verilerinden 1525 adet veri kullanılmıştır. Çalışmada denetim kalitesi göstergesi olarak denetim firması büyüklüğ̈ ve denetim ücreti kullanılmıştır. Kar yönetiminin ölçümünde ise isteğe bağlı tahakkuklar kullanılmıştır. Ampirik analizlerde regresyon analizi yönteminden yararlanılmıştır. Yapılan analiz sonucunda kar yönetimi ile denetim kalitesi göstergesi olarak kullanılan denetim firması büyüklügü arasında negatif ve istatiksel olarak anlamlı bir ilişki olduğu belirlenmiştir. Buna karşın kar yönetimi ile denetim kalitesinin bir diğer göstergesi olan denetim ücreti arasında pozitif bir ilişki olduğu tespit edilmiştir. Ayrıca çalışmada kontrol değişkeni olarak kullanılan firma büyüklüğ̈̈, borçlanma oranı ve karlılık oranı ile kar yönetimi arasında ilişki olduğu ortaya konmuştur.

Anahtar Kelimeler: Denetim, denetim kalitesi, kar yönetimi

JEL Sinıflandırması: M40, M41, M42.

\section{The Impact Of Independent External Audit Quality On Earnings Management: An} Application On BIST-100 Companies

\section{ABSTRACT}

The basic purpose of this study is to identify the relation between audit quality and earnings management. In order to fulfill this purpose, 1525 data from the annual data of firms belonging to different sectors which are traded in Borsa Istanbul BIST 100 index covering the years of 2009-2015 were used. Audit firm size and audit fees were used as the indicators quality of audit this study. Discretionary accruals were used during the measurement of earnings management. The regression analysis method was used during empirical analyses. Pursuant to the analysis made, a meaningful relation was found in negative and statistical terms between earnings management and audit firm size, which was used as the indicator of audit quality. On the other hand, a positive relation was found between earnings management and audit fees, which is another indicator of audit quality. The study further found that a relation existed between earnings management and firm size, debt ratio and profitability ratio, which are used as control variables.

Keywords: Audit, audit quality, earnings management

Jel Classification: M40, M41, M42.

Makale Türü: Araştırma makalesi

\footnotetext{
* Dr. Öğr. Üyesi, Van Yüzüncü Y1l Üniversitesi, İktisadi ve İdari Bilimler Fakültesi, ayselakcay@yyu.edu.tr , ORCID ID: 0000-0001-9655-5673.

** Prof. Dr., Dicle Üniversitesi, İktisadi ve İdari Bilimler Fakültesi, abilen@ dicle.edu.tr, ORCID ID: 0000-00022619-9331.
} 


\section{GíRİş}

2001 yılında Amerika Birleşik Devletlerinde (ABD) yaşanan Enron skandalı muhasebe ve denetim alanında çığır açmıştır. Enron ve daha sonrasında Worldcom, Global Crossing, Tyco, Cerox gibi firmalarda yaşanan skandallara yönelik yapılan incelemelerde söz konusu firmaların finansal raporları ve bunları denetleyen denetim şirketleri ile ilgili önemli bulgular elde edilmiştir. Bu skandalların incelenmesi amacıyla yapılan çalışmalarda firmaların finansal durumlarını daha iyi göstermek adına hata ve hilelere başvurduğu ve Arthur Andersen başta olmak üzere birçok denetim firmasının yapılan bu hata ve hileleri göz ardı ettiğine dair önemli kanıtlara ulaşılmıştır. Bu durum işletme yönetimine, finansal raporlara ve söz konusu firmaların denetimini yapan bağımsız denetim şirketlerine olan güveni oldukça azaltmıştır. Bu nedenle bağımsız denetimin daha kaliteli yapılması amacıyla muhasebe ve denetim sisteminde değişiklik ve düzenlemelere gidilmiştir. Böylece Enron olayına benzer bir skandalın tekrar yaşanmaması adına Sarbane's Oxley Kanunu başta olmak üzere Avrupa Birliği ülkelerinde ve Türkiye'de kamu otoriteleri tarafından yeni düzenlemeler yürürlüğe konulmuştur. Bu yeni düzenlemelerin amacı sermaye piyasalarına karşı oluşan güven kaybını azaltmak ve borsada işlem gören firmaların finansal raporlarının şeffaflık, güvenilirlik gibi sorumlulukları yerine getirmelerini sağlamaktır.

Kar yönetimi; bazı özel kazançlar elde etmek amacıyla finansal raporlama sürecine kasitlı olarak yapılan bir müdahale olarak tanımlanabilir (Schipper, 1989: 92). Finansal raporlamanın amaçlarından biri yatırımcılara, alacaklılara ve diğer mevcut ve potansiyel yatırımcılara firma hakkında bilgi sağlamaktır. Ancak yöneticilerin firma ve /veya yönetici çıkarlarını korumak amacıyla finansal raporlama sürecinde kar yönetimi uygulamalarına yönelmesi şirket finansal tablolarından yararlanan yatırımcı, çalışanlar, kredi verenler gibi bilgi kullanıcılarının kararlarında yanılmalarına neden olmaktadır. Yöneticilerin kar yönetimi uygulamaları ile firma performansını olduğundan farklı göstermesi ise finansal tabloların şeffaflık ve güvenilirliğini olumsuz yönde etkilemektedir. Bu bağlamda yönetici tarafindan ileri sürülen bilgilerin doğrulunun tespit edilebilmesi için yapılan denetimlerin kaliteli olması büyük önem taşımaktadır.

Bağımsız denetim kalitesi, denetim firması tarafından müşteri işletmenin mali tablolarına ait bilgilerin yasal düzenlemelere uygun olarak hazırlanıp hazırlanmadığını tespit etmek ve bu doğrultuda finansal tablo kullanıcılarına makul bir güvence sağlamak açısından son derece önemlidir. Genel olarak bağımsız dış denetimin amacı pay sahiplerinin çıkarlarını finansal tablolarda yapılan hata ve hilelere karşı korumaktır.

Denetim kalitesinin evrensel olarak kabul edilmiş bir tanımı olmasa da DeAngelo (1981) denetim kalitesini; a) Finansal tablolardaki hata ve hileleri tespit etmek ve b) bulunan önemli hata ve hilelerin rapor edilmesinin piyasa tarafından değerlenen olasılığı olarak tanımlamaktadır. Bu tanımdan hareketle denetim kalitesi hem denetçi yetkinliğinin hem de denetçi bağımsızlığının bir işlevi olarak görülür. Denetçinin finansal tablolarda yapılan hata ve hileleri tespit etme olasıllğı denetçi yetkinliğinin bir ölçütü iken bunları rapor etme ihtimali ise denetçi bağımsızlık düzeyinin bir ölçüsüdür (DeAngelo, 1981: 186). Ancak denetim kalitesinin bu iki unsuru doğrudan gözlemlenemediğinden, ilgili çalışmalarda denetim kalitesi genellikle dolaylı olarak ölçülmüştür. Konu ile ilgili literatür incelendiğinde denetim kalitesini ölçmek için birçok gösterge kullanılsa da en yaygın olarak kullanılan denetim 
kalitesi göstergeleri bu çalışmada olduğu gibi denetim firması büyüklüğü ve denetim ücretidir.

Yukarıdaki teorik tartışmalardan hareketle bu çalışmanın amacı denetim kalitesi ve kar yönetimi arasındaki ilişkiyi incelemektir. $\mathrm{Bu}$ amaç doğrultusunda 2009-2015 yıllarını kapsayan ve Borsa İstanbul'a kayıtlı farklı sektörlere ait 1525 y1llık veri gözleminden yararlanılmıştır. Kullanılan tüm verilerin elde edilmesinde Kamuyu Aydınlatma Platformu'nun resmi web sayfasından (www.kap.gov.tr) yararlanılmıştır. Çalışmada denetim kalitesi göstergesi olarak denetim firması büyüklüğü ve denetim ücreti kullanılmıştır. Kar yönetimi göstergesi olarak ise literatür ile tutarlı bir biçimde (Caramanis ve Lennox,2008; Karacaer ve Özek, 2010; Gerayli, Yanesari ve Ma'atoofi, 2011; Yaşar, 2011; Ahmad vd., 2016) isteğe bağlı tahakkuklar kullanılmıştır. İsteğe bağlı tahakkukların hesaplanmasında sonraki kısımlarda detaylı olarak açıklanmış olan "Modifiye Edilmiş Jones Modeli" kullanılmıştır. Firma büyüklügü̈, borçlanma ve karlılık oranları ise literatür ile tutarlı bir şekilde (Becker vd, 1998; Karacaer ve Özek, 2010, Nawaiseh, 2016) kontrol değişkeni olarak kullanılmıştır. Yapılan ampirik analiz sonucunda kar yönetimi ile denetim kalitesi göstergesi olarak kullanılan denetim firması büyüklügü arasında negatif ve istatiksel olarak anlamlı bir ilişki bulunmuştur. Buna karşın kar yönetimi ile denetim kalitesi göstergesi olarak kullanılan denetim ücreti arasında pozitif fakat istatiksel olarak anlamlı olmayan bir ilişki olduğu belirlenmiştir.

Çalışma beş bölümden oluşmaktadır. Girişi takiben ikinci bölümde denetim kalitesi göstergeleri olarak kullanılan denetim firması büyüklüğ̈̈ ve denetim ücreti ile kar yönetimi arasındaki ilişkilerin incelendiği literatürde yer alan çalışmalar incelenmiştir. Üçüncü bölümde araştırma tasarımı hakkında bilgi verilmiştir. Dördüncü bölümde analiz sonuçları yer almaktadır. Son bölümde ise genel değerlendirme yapılmıştır.

\section{LITERATÜR TARAMASI}

\subsection{Denetim Kalitesi ve Kar Yönetimi}

Bağımsız denetimin en önemli amaçlarından birisi işletmelerin finansal tablo kullanıcılarına doğru ve güvenilir bir bilgi sağlayarak piyasada güven ortamının oluşmasını sağlamaktır. $\mathrm{Bu}$ bağlamda bağımsız denetçi denetlenen firmanın finansal tablolarının muhasebe standartlarına uygun olarak hazırlandığını ve bu tabloların firmanın gerçek finansal durumunu yansıttığını doğrulama konusunda önemli bir role sahiptir. Denetçinin bu sorumluluğu yerine getirebilmesi ise denetimin kaliteli bir şekilde yapılmış olmasına bağlıdır. Kar yönetimi uygulamaları yatırımcıların ve finansal tablo kullanıcılarının şirketin mali durumu ve faaliyet sonuçları hakkında algılarını etkilemek amacıyla yapılmaktadır. Bu durum ise ekonomik kaynakların yanlış tahsisine neden olabilmektedir. 2001 yılında yaşanan Enron skandalı ve sonrasinda devam eden Wordcom, Xerox, Parmalat, Ahold, Kanebo vb. skandalların temelinde kar yönetiminin etkili olması denetim kalitesinin önemini artırmıştır. $\mathrm{Bu}$ nedenle birçok çalışma finansal tabloların kalitesine ve özellikle "öncelikli bilgi" olarak kabul edilen muhasebe kazançlarına odaklanmıştır. Bunun sonucu olarak da, denetim kalitesi ve kar yönetimi ilgi çeken bir konu olmuştur.

Denetim kalitesinin literatürde farklı göstergeler ile ölçüldüğü görülmektedir. Ancak son yıllarda yapılan çalışmaların önemli bir kısmında (bu çalışmada olduğu gibi) denetim 
kalitesi göstergesi olarak denetim firması büyüklüğü ve denetim ücretlerinin kullandığını görülmüştür. Bu nedenle literatürde yer alan ve aşağıda özetlenen çalışmalar denetim kalitesi göstergesi olarak denetim firması büyüklügü̈ ve denetim ücreti olarak iki alt başlık altında özetlenmiş ve hipotezler geliştirilmiştir.

\subsubsection{Denetim Kalitesi Göstergesi Olarak Denetim Firması Büyüklüğünün Kullanıldığı Çalışmalar}

DeAngelo (1981: 188) çalışmasında büyük denetim firmalarının yanlış bildirimleri algılama ve ortaya çıkarma konusunda daha fazla teşvike sahip olduklarını belirtmiştir. Çünkü büyük denetim firmaları daha şöhretli oldukları için şirketlerin finansal tablolarında yapmış oldukları hata ve hileleri ortaya çıkarma konusunda daha isteklidirler. Zira söz konusu denetim firmalarının gerçeği yansıtmayan bir rapor yayımlaması büyük müşteri kayıplarına yol açabilecektir. Bu nedenle piyasadaki itibarını ve güvenini kaybetmek istemeyen büyük denetim firmalarının müşteri işletmenin finansal tablolarında yapmış olduğu hata ve hileleri ortaya çıkarma ve bunu rapor etme olasılığının daha yüksek olduğu ileri sürülmektedir. Bunun yanında yüksek varlık düzeylerine sahip olan denetçiler bu varlıklarını olası bir dava riskine karşı korumak amacıyla doğru ve güvenilir denetim raporları yayımlama eğilimindedirler.

DeAngelo'nun (1981) denetim kalitesi göstergesi olarak denetim firması büyüklüğünü kullandığı çalışmadan sonra konuyla ilgili yapılan birçok araştırmada denetim kalitesi göstergesi olarak bu ölçütün kullanıldığı görülmektedir. Aşağıda denetim firması büyüklüğü ve kar yönetimi arasındaki ilişkiyi inceleyen literatürde öne çıkmış çalışmalar ve sonuçları gösterilmektedir.

Becker vd. (1998), 1989-1992 yıllarını kapsayan ve 10.379'u, 6 büyük denetim firması, 2.179'u, 6 büyük denetim firması dışındaki denetim firmalarınca denetlenen firma verilerinin kullanıldığ çalışmalarında, 6 büyük denetim firması tarafından denetlenmeyen firmaların daha fazla kar yönetimi uyguladığı sonucuna ulaşmışlardır.

Zhou ve Elder (2001), 1991-1999 yıllarını kapsayan 2453 firma yıllık verisi gözleminden yararlandıkları çalışmalarında denetim firması büyüklüğü ve kar yönetimi arasında negatif bir ilişki olduğunu tespit etmişlerdir.

Bauwhede vd. (2003), 1991-1997 yıllarını kapsayan 136 firma verisini kullandıkları çalışmalarında diğer çalışmalardan farklı olarak hem halka açık olan, hem de halka açık olmayan şirketlerin verilerini kullanmışlardır. Yapılan analiz sonucunda Belçika'nın kurumsal yapısının farklı olması sebebiyle denetçilere yönelik tazminat davasının olmaması denetçilerin karı artırıcı kar yönetimi uygulamalarını sınırlandırma konusunda muhafazakâr davranmadığı, karı azaltıcı kar yönetimi uygulamalarında ise vergi otoritelerinden çekinmeleri dolayısıyla 6 büyük (Big 6) denetim firmasının kar yönetimini sınırlandırdığı sonucuna ulaşılmıştır.

Jeong ve Rho (2004) çalışmalarında, 1994-1998 yıllarını kapsayan ve Kore Menkul Kıymetler Borsası'na kayıtlı 2.117 firma yılı gözleminden yararlanmışlardır. Yapılan analiz sonucunda Kore'de yüksek kalitede denetimi sağlayacak izleme mekanizmalarının olmaması nedeniyle altı büyük denetim firması tarafından denetlenen şirketlerin kar yönetimi ile 
diğerleri tarafından denetlenen şirketlerin kar yönetimi arasında önemli bir fark olmadığ sonucuna ulaşılmıştır.

Cai vd. (2005), 2002 yılında Şangay Borsası'nda işlem gören 343 firma verisinden yararlandıkları çalışmalarında denetim kalitesi ve kar yönetimi arasında negatif bir ilişki olduğunu tespit etmişlerdir. Başka bir deyişle 10 büyük denetim firmasının diğer denetim firmalarına göre kar yönetimini daha fazla kısıtladığı sonucuna ulaşılmıştır.

Chen, vd. (2006), Tayvan firmaları üzerine yapmış oldukları çalışmada denetçi itibarı ve endüstri uzmanlığı ile kar yönetimi arasındaki ilişkiyi incelemişlerdir. Denetçi itibarı göstergesi olarak beş büyük denetim firması kullanılmıştır. 1998-2002 yıllarını kapsayan ve 2.324 firma yılı gözleminden yararlandıkları çalışmada beş büyük denetim firmasının kar yönetimini kısıtladığı sonucuna ulaşmışlardır.

Tendeloo ve Vanstraelen (2008), yapmış oldukları çalışmada halka açık olmayan şirketlerde dört büyük denetim firmasının kar yönetimini sınırlandırıp sınırlandırmadığını incelemişlerdir. 1998-2000 yıllarını kapsayan çalışmada 6 Avrupa ülkesine ait (Belçika, Finlandiya, Fransa, Hollanda, İspanya ve İngiltere) 64.831 firma y1lı gözleminden yararlanılmıştır. Yapılan analiz sonucunda yüksek vergi grubundaki ülkelerde denetim firması büyüklüğü ile kar yönetimi arasında negatif bir ilişki olduğu belirlenmiştir.

Karacaer ve Özek (2010), BİST'e kayıtlı şirketler üzerinde 2005-2008 yıllarına ait 645 firma verisini kullandıkları çalışmalarında denetim firması büyüklüğü ile kar yönetimi arasında negatif ve istatiksel olarak anlamlı bir sonuç elde etmişlerdir.

Chen vd. (2011), Çin'deki kamu işletmeleri (SOEs) ile kamuya ait olmayan işletmelerde (NSOEs) denetim kalitesinin kar yönetimi ve öz kaynak maliyeti üzerine etkisini inceledikleri çalışmalarında 2001- 2004 yıllarını içeren 3.310 firma verisinden yararlanmışlardır. Çalışmada sekiz büyük (Big 8) denetim firması tarafından denetlenen firmaların kar yönetiminin diğer denetim firmaları ile denetlenen firmalara göre daha az olduğu tespit edilmiştir.

Namazi vd. (2011), Tahran Borsası üzerine yapmış oldukları 2002-2008 yıllarını kapsayan ve 62 firma verisinden yararlandıkları çalışmalarında denetim firması büyüklüğü ve kar yönetimi arasında pozitif fakat istatiksel olarak anlamlı bir ilişki elde edememişlerdir.

Yaşar (2011), 2003-2007 yıllarını kapsayan ve İMKB'ye kayıtlı 290 firma yılı gözleminden yararlandığı çalışmasında denetim firması büyüklüğü ile kar yönetimi arasında bir ilişki olmadığı sonucuna ulaşmıştır.

Gerayli vd. (2011), çoklu regresyon modelini kullandıkları çalışmalarında denetim kalitesinin kar yönetimi ölçütü olarak kullanılan isteğe bağlı tahakkuklar üzerindeki etkisini araştırmışlardır. Denetim kalitesinin üç farklı göstergesinin kullanıldığı (denetçi büyüklüğü, denetçi endüstri uzmanlığı ve denetçi bağımsızlığı) 2004- 2009 yıllarını kapsayan çalışmada Tahran borsasında işlem gören 540 firma verisinden yararlanılmıştır. Yapılan analiz sonucunda kar yönetimi ile denetim kalitesi arasında negatif yönde bir ilişkinin olduğu tespit edilmiştir. 
Zgarni vd. (2012), 2000-2010 yıllarını kapsayan ve 319 firma verisinden yararlandıkları çalışmalarında denetim kalitesinin gerçek ve tahakkuk esaslı kar yönetimi üzerindeki etkisini incelemişlerdir. Denetim kalitesi göstergesi olarak dört büyük denetim firması, sektörel uzmanlık ve denetim sürelerinin kullanıldığı çalışma sonucunda denetçi endüstri uzmanlığı ve dört büyük denetim firmasının kar yönetimini azalttığı sonucuna ulaşılmış̧ır. Bunun yanında denetçi çalışma süresinin uzunluğu ile kar yönetimi arasında bir ilişsi tespit edilememiştir.

Memiş ve Çetanak (2012), 2008-2009 yıllarını kapsayan ve gelişmekte olan 8 farklı ülkenin 1.507 yıllık firma verisi gözleminden yararlandıkları çalışmalarında dört büyük denetim firmasının her ülkede kar yönetimi uygulamalarını kısıtlamadığı sonucuna ulaşı1mıştır.

Pouraghajan vd. (2013), 2006-2011 yıllarını kapsayan çalışmalarında Tahran Borsası'na kayıtlı 840 yıllık firma verisi gözleminden yararlanmışlardır. Yapılan analiz sonucunda denetim kalitesi göstergesi olarak kullanılan denetim firması büyüklüğü ile kar yönetimi arasında anlamlı bir ilişki bulunamamıştır.

Chen vd. (2014), Çin firmaları üzerine yapmış oldukları 2001-2009 yıllarını kapsayan ve 8.788 yıllık firma verisi gözleminden yararlandıkları çalışmalarında denetim firması büyüklüğünün kar yönetimi ile negatif ilişkili olduğu sonucuna ulaşmışlardır.

Zuo ve Guan (2014), denetim firması büyüklüğü ve denetçi endüstri uzmanlığının kar yönetimi üzerine etkisini inceledikleri çalışmalarında 4.640 yıllık firma verisi gözleminden yararlanmışlardır. 2008-2011 yıllarını kapsayan çalışmada denetim firması büyüklüğü ile kar yönetimi arasında negatif ve istatiksel olarak anlamlı bir sonuç elde edilmiş̧ir.

Endonezya firmaları üzerine yapmış oldukları çalışmalarında Gumanti vd. (2015) denetim kalitesi ve kar yönetimi arasındaki ilişkiyi incelemişlerdir. 2000-2006 yıllarını kapsayan çalı̧̧ma sonucunda denetim kalitesi ve kar yönetimi arasında negatif ve istatiksel olarak anlamlı bir ilişki elde etmişlerdir.

Affes ve Smii (2016), Tunus Menkul Kıymetler Borsası'na kayıtlı 20 firmanın 20052009 yıllarına ait verilerini kullandıkları çalışmalarında denetim kalitesinin kar yönetimini azalttığı sonucuna ulaşmışlardır.

Abbasiazadeh ve Zamanpour (2016), 2010-2014 yıllarını kapsayan ve Tahran Borsası'na kayıtlı 116 firma verisinin kullanıldığı çalışmada denetim firması büyüklüğü ile kar yönetimi arasındaki ilişkiyi incelemişlerdir. Yapılan analiz sonucunda denetim firması büyüklüğü ile kar yönetimi arasında negatif ve istatiksel olarak anlamlı bir ilişki olduğu tespit edilmiştir.

Ahmad vd. (2016), 2010-2013 yıllarını kapsayan ve Endonezya Borsası'nda işlem gören 420 yıllık firma verisi kullandıkları çalışmalarında denetim kalitesi ve kar yönetimi arasındaki ilişkiyi incelemişlerdir. Yapılan analiz sonucunda denetim kalitesi ve kar yönetimi arasında negatif ve anlamlı bir ilişki olduğu tespit edilmiştir. 
Al-Quda vd. (2017) 2009-2015 yıllarını kapsayan ve 59 Ürdün firması verisinden yararlandıkları çalışmalarında denetim firması büyüklüğü ile kar yönetimi arasında negatif bir ilişki olduğunu tespit etmişlerdir.

Yukarıdaki çalışmalar doğrultusunda aşağıdaki hipotez geliştirilmiştir:

H1: Denetim firması büyüklügü ile kar yönetimi arasında anlamlı bir ilişki vardır.

\subsubsection{Denetim Kalitesi Göstergesi Olarak Denetim Ücretinin Kullanıldığı Çalışmalar}

Denetim ücreti ve kar yönetimi üzerine yapılan ve literatürde özetlenen çalışmalarda denetim ücretinin kar yönetimi üzerinde önemli bir etkiye sahip olduğu ortaya konmuştur. Tahakkuklar ticari alacaklar ve stoklar gibi yüksek riskli hesaplarla ilişkili olduğu için ihtiyari tahakkukların tespit edilmesi denetçiler tarafından ortak bir sorun olarak görülmektedir. Kar yönetimi uygulayan bir şirketin isteğe bağlı tahakkuklarının tespit edilmesi denetçilerin daha fazla kanıt toplaması, daha deneyimli ve yetenekli denetçiler ile daha kapsamlı bir denetim hizmeti sunmasını gerektirecektir. Bu da denetim firmasının daha yüksek denetim ücreti talep etmesine neden olabilecektir. Aşağıda denetim firması büyüklüğü ve kar yönetimi arasındaki ilişkiyi inceleyen literatürde öne çıkmış çalışmalar ve sonuçları gösterilmektedir.

Frankel vd. (2002) tarafından yapılan ve 3.074 gözlemden yararlanılan çalışmada denetim ücreti ile kar yönetimi arasında negatif bir ilişki bulunurken; denetim dışı ücretler ile kar yönetimi arasında pozitif bir ilişki olduğu sonucuna ulaşılmıştır.

Li ve Lin (2005), 2000 yılına ait 351 firma verisini kullandıkları çalışmalarında denetim ücreti ile kar yönetimi arasında pozitif bir ilişki olduğunu tespit etmişlerdir.

Antle vd. (2006), 1994-2000 yıllarını kapsayan ve UK firmalarına ait 2.294 firma verisi gözleminden yararlandıkları çalışmalarında denetim ücretleri ve denetim dışı ücretler ile kar yönetimi arasındaki ilişkiyi incelemişlerdir. Yapılan analiz sonucunda denetim ücreti ile kar yönetimi arasında pozitif bir ilişki olduğu sonucuna ulaşılmıştır.

Schelleman ve Knechel (2010), 1997 yılına ait 119 Hollanda firma verisinden yararlandıkları çalışmalarında denetim ücreti ve kar yönetimi arasında pozitif bir ilişki tespit etmişlerdir.

Alali (2011), 2000-2006 yıllarını kapsayan çalışmada 36.218 yıllık firma verisi gözleminden yararlandığı çalışmasında, denetim ücreti ve kar yönetimi arasında pozitif ve anlamlı bir ilişki elde etmiş̧tir.

Greiner vd. (2013), 2004-2011 y1llarını kapsayan ve 22.608 firma verisini kullandıkları çalışmalarında kar yönetimi ile denetim ücreti arasında pozitif bir ilişki olduğu sonucuna varmışlardır.

$\mathrm{Gu}$ ve $\mathrm{Hu}$ (2015), Amerika Birleşik Devletlerinde faaliyet gösteren Japon firmaları üzerine yapmış oldukları çalışmada 2005-2013 yıllarını kapsayan 12.225 firma verisi gözleminden yararlanmışlardır. Yapılan analiz sonucunda denetim ücreti ve kar yönetimi arasında pozitif bir ilişki olduğu tespit edilmiştir. 
Martinez ve Moraes (2017), 2009-2010 yıllarına ait 300 Brezilya firma verisi kullandıkları çalışmalarında denetim ücreti ile kar yönetimi arasında negatif bir ilişki olduğu sonucuna ulaşmışlardır.

Yukarıdaki çalışmalar doğrultusunda aşağıdaki hipotez geliştirilmiştir:

H2: denetim ücreti ve kar yönetimi arasinda anlamlı bir ilişki vardır.

\section{ARAŞTIRMA TASARIMI}

Çalışmanın bu kısmında, örneklem, araştırma modeli ve değişkenlerin hesaplanmasına ilişkin prosedür açıklanmıştır.

\section{1.Örneklem}

Çalışmada Borsa İstanbul BİST 100 endeksinde işlem gören farklı sektörlerde yer alan ve ilgili dönemlerde süreklilik gösteren firma verilerinden yararlanılmışır. Varlık yapılarının farklı olması dolayısıyla finans sektöründe yer alan firmalar kapsam dı̧̧ı tutulmuştur. 20092015 yıllarını kapsayan çalışmada aşağıda tanımlamaları yapılan tüm değişkenlere ilişkin veriler Kamuyu Aydınlatma Platformu'nun resmi web sayfasindan (www.kap.gov.tr) sağlanmıştır. Söz konusu kısıtlamalar doğrultusunda 1.525 firma verisi kullanılarak elde edilen örneklemde her yıl inceleme konusu olan firma sayısı farklı olmuştur. Tablo 1'de araştırma kapsamında kullanılan firma yılları gösterilmiştir.

Tablo 1. Örneklem Kapsamında Kullanılan Firma Verileri

\begin{tabular}{|c|c|}
\hline Yıllar & Gözlem sayısı \\
\hline 2009 & 250 \\
2010 & 250 \\
2011 & 258 \\
2012 & 258 \\
2013 & 293 \\
2014 & 108 \\
2015 & 108 \\
\hline Toplam & $\mathbf{1 5 2 5}$ \\
\hline
\end{tabular}

Ancak denetim kalitesi göstergesi olarak denetim ücretinin kullanıldığı modelde örneklem hacmi düşüktür. Denetim ücreti ile ilgili gerekli verilere firma mali tablolarından ulaşılamadığından firmalar ile telefon ve e-posta yoluyla kurulan iletişim sonucunda yaklaşık 54 firmanın 2014-2015 yıllarına ait denetim ücreti verilerine ulaşılmışıır.

\subsection{Araştırma Modeli}

Denetim kalitesi ve kar yönetimi arasındaki ilişkiyi inceleyen bu çalışmada geliştirilen hipotezleri test etmek amacıyla regresyon analizi kullanılmış ve aşağıdaki modeller oluşturulmuştur: 
MODEL 1: DA it $=\beta 0+\beta 1$ BIG4 it $+\beta 2$ LEV it $+\beta 3$ SIZE it $+\beta 4$ ROA it $+\varepsilon$ it

MODEL 2: DA it $=\beta 0+\beta 1 \ddot{U} C R E T$ it $+\beta 2$ LEV it $+\beta 3$ SIZE it $+\beta 4$ ROA it $+\varepsilon$ it

Burada; DA, t döneminde i firmasının isteğe bağlı tahakkuklarını; BIG4, $t$ döneminde i firmasının denetim firması büyüklüğünü; ÜCRET, t döneminde i firmasının denetim ücretini; $\mathrm{LEV}, \mathrm{t}$ döneminde i firmasının borçlanma oranını; ROA, $\mathrm{t}$ döneminde i firmasının karlılık oranını; SIZE, $\mathrm{t}$ döneminde i firmasının firma büyüklüğünü ve cit ise hata terimini göstermektedir.

\subsection{Değişkenler}

\subsubsection{Bağımlı Değişken}

Çalışmada bağımlı değişken olarak kar yönetimi kullanılmıştır. Kar yönetimi üzerine daha önceki yıllarda yapılan çalışmalarda (Caramanis ve Lennox,2008; Karacaer ve Özek, 2010; Gerayli vd., 2011; Yaşar, 2011; Ahmad vd., 2016) olduğu gibi bu çalışmada da kar yönetiminin ölçümünde isteğe bağlı tahakkuklar kullanılmıştır. Bunun için Jones (1991) tarafından oluşturulan ve daha sonra Dechow vd. (1995) tarafından geliştirilen aşağıdaki Modifiye Edilmiş Jones Modeli uygulanmıştır.

$$
D A \text { it }=(T A \text { it } / A \text { it }-1)-[\beta 1(1 / A \text { it-1 })]+\beta 1 i[(\triangle R E V \text { it }-\triangle R E C \text { it }) / A \text { it }-1]+\beta 2 i
$$

[PPE t/A it-1]

Burada, $\mathrm{DA}_{i t}, \mathrm{t}$ döneminde i firmasının isteğe bağlı tahakkuklarını, $\mathrm{TA}_{i t}, \mathrm{t}$ döneminde $\mathrm{i}$ firmasının toplam tahakkuklarını, $\Delta \mathrm{REV}_{i t}, \mathrm{t}$ döneminde $\mathrm{i}$ firmasının satış gelirlerindeki değişimi, $\Delta \mathrm{REC}_{i t}$, t döneminde i firmasının ticari alacaklarındaki değişimi, $\mathrm{PPE}_{i t}, \mathrm{t}$ döneminde i firmasının maddi duran varlıkları $A_{i t-1}$, $t-1$ döneminde $i$ firmasının toplam varlıklarını göstermektedir.

\subsubsection{Bağımsız Değişskenler}

Çalışmada temel bağımsız değişken olarak denetim kalitesi kullanılmıştır. Denetim kalitesi kavramının belirsiz ve çok boyutlu olması denetim kalitesinin doğrudan ölçülmesini zorlaştırmıştır. $\mathrm{Bu}$ nedenle literatürde denetim kalitesi; denetim ücreti (Simunic, 1980; Palmrose, 1986; Li ve Lin, 2005), denetim saati (Kramer vd., 2011; Okolie, 2014; Bamahros ve Wan-Hussin, 2015), denetçi itibarı (Kanagaretnam vd., 2010),denetçi rotasyonu (Martinez ve Reis, 2010; Nicolaescu, 2014) sektörel uzmanlaşma (Rusmin, 2010; Chen vd., 2006) ve denetim firması büyüklüğü ( Becker vd., 1998; Elder ve Zhou, 2002;Yaşar, 2011; Memiş ve Çetenak, 2012; Ahmad vd., 2016) gibi göstergelerle dolaylı olarak ölçülmüştür.

Denetim kalitesi üzerine yapılan çalı̧̧maları özetleyen Hay vd. (2006), denetim kalitesi ölçümünde en önemli göstergelerin denetim firması büyüklüğü ve denetim ücreti olduğunu ifade etmişlerdir. Bu çalışmada da denetim kalitesi göstergesi olarak söz konusu iki gösterge (denetim firması büyüklüğü ve denetim ücretleri) dikkate alınmış ve aşağıdaki gibi hesaplanmıştır. Daha önceki çalışmalarda denetim kalitesini ölçmek için kullanılan diğer değişkenler veri eksikliği ve diğer kısıtlamalar nedeniyle modele dahil edilememiş̧tir. 


\subsubsection{Denetim Firması Büyüklüğü}

Bu çalışmada, denetim kalitesi göstergelerinden biri olarak denetim firması büyüklüğü (BIG4) kullanılmıştır. Kukla değişken olarak kullanılan BIG4 şöyle hesaplanmıştır:

BIG4; firmanin 4 büyük denetim firması tarafindan denetlenmesi durumunda 1 aksi halde 0 değerini almaktadır. Araştırma kapsamında BIG4 olarak kullanılan denetim firmaları PricewaterhouseCoopers, Ernst \&Young, Deloitte \& Touche ve KPMG'dir.

\subsubsection{Denetim Ücreti}

Denetim ücreti ile ilgili gerekli verilere firma mali tablolarından ulaşılamadığından firmalar ile telefon ve e-posta yoluyla kurulan iletişim sonucunda sadece akademik çalışmada kullanılması ve firma isimlerinin saklı tutulması koşuluyla yaklaşık 54 firmanın 2014-2015 yıllarına ait denetim ücreti verilerine ulaşılmıştır. Söz konusu firmaların ilgili yıllarına ait denetim ücreti aşă̆ıda gösterildiği gibi hesaplanmıştır:

ÜCRET = Ilgili dönemdeki denetim ücreti / toplam giderler

\subsubsection{Kontrol Değişkenleri}

Çalışmada ayrıca kar yönetimi üzerinde etkisi olduğu düşünülen üç kontrol değişkeni kullanılmıştır. Firmaların ilgili yıllardaki mali tablolarından elde edilen bu değişkenler aşağıda gösterildiği gibi hesaplanmıştır:

KARLILIK= Net Kar it/ Toplam Varliklar it

KALDIRAÇ $=($ Kisa Vadeli Borçlar it + Uzun Vadeli Borçlar it $) /$ Toplam Varlıklar it

$B \ddot{U} Y \ddot{U K L} \ddot{U} K=$ Firma toplam varlıklarının doğal logaritmast

\section{AMPÍRIKK ANALIZ VE BULGULAR}

Tablo 2'de denetim kalitesi göstergesi olarak kullanılan denetim firması büyüklüğüne ilişskin tanımlayıcı istatistik sonuçları yer almaktadır. Tablo 3'te denetim kalitesinin diğer göstergesi olan denetim ücretine ait tanımlayıcı istatistik sonuçları yer almaktadır. Tablo 4 'te ise 4 büyükler (BIG4) ile diğer denetim firmaları tarafından denetlenen firmaların (NONBIG4) tanımlayıcı istatistiklerin karşılaştırılmasına ilişkin $t$ testi sonuçları yer almaktadır. 
Tablo 2. BIG4 Tanımlayıcı İstatistikler

\begin{tabular}{|c|c|c|c|c|c|}
\hline DEĞiŞKENLER & $\begin{array}{c}\text { Gözlem } \\
\text { sayısı }\end{array}$ & Minimum & Maksimum & Ortalama & $\begin{array}{c}\text { Standart } \\
\text { sapma }\end{array}$ \\
\hline TAHAKKUK & 1525 & $-1,26$ &, 97 &,- 0104 &, 14351 \\
\hline BIG4 & 1525 & 0 & 1 &, 4531 &, 49796 \\
\hline LEV & 1525 &, 01 &, 99 &, 4694 &, 23883 \\
\hline SIZE & 1525 & 5,71 & 10,27 & 8,0612 &, 78324 \\
\hline ROA & 1525 &,- 90 &, 84 &, 0304 &, 10488 \\
\hline
\end{tabular}

Tablo 2 sonuçları incelendiğinde isteğe bağlı tahakkukların maksimum 0,97 minimum -1,26 değerlerini aldığı görülmektedir. Ayrıca analiz kapsamında yer alan firmaların yaklaşık \%45'inin dört büyük denetim firması tarafından denetlendiği görülmektedir. Öte yandan kontrol değişkeni olarak kullanılan LEV, SIZE ve ROA ortalamaları ise sırasıyla $\% 46, \% 8$ ve $\% 0,3$ ' tür.

Tablo 3. Denetim Ücretine İlişkin Tanımlayıcı İstatistikler

\begin{tabular}{|c|c|c|c|c|c|}
\hline DEĞiŞKENLER & Gözlem sayısı & Minimum & Maksimum & Ortalama & $\begin{array}{c}\text { Standart } \\
\text { sapma }\end{array}$ \\
\hline TAHAKKUK & $\mathbf{1 0 8}$ &,- 49 &, 43 &, 0073 &, 11774 \\
\hline ÜCRET & $\mathbf{1 0 8}$ &, 01 &, 10 &, 0565 &, 02329 \\
\hline LEV & $\mathbf{1 0 8}$ &, 02 &, 93 &, 4766 &, 21683 \\
\hline SİZE & $\mathbf{1 0 8}$ & 5,98 & 9,05 & 8,1156 &, 59948 \\
\hline ROA & $\mathbf{1 0 8}$ &,- 11 &, 34 &, 0464 &, 08226 \\
\hline
\end{tabular}

Tablo 3'te ise isteğe bağlı tahakkukların -0,49 ile 0,43 arasında olduğu görülmektedir. Denetim kalitesi göstergesi olarak kullanılan denetim ücretinin minimum 0,01 maksimum 0,10 değerlerini aldığ 1 ve ortalama değerinin 0,05 olduğu görülmektedir. Analiz kapsamında incelenen firmaların LEV, SIZE ve ROA ortalamaları ise sirasıyla 0,47, 8,11 ve 0,04'tür.

Tablo 4. Tanımlayıcı İstatistikler (Karşılaştırmalı)

\begin{tabular}{|c|c|c|c|}
\hline & $\begin{array}{c}\text { (A) } \\
\text { Big4 } \\
(\mathbf{N = 6 9 1})\end{array}$ & $\begin{array}{c}\text { (B) } \\
\text { NonBig4 } \\
(\mathbf{N = 8 3 4})\end{array}$ & $\begin{array}{c}\text { (C) } \\
\text { Fark } \\
\text { A=B }\end{array}$ \\
\hline TAHAKKUK & Ortalama & Ortalama & t istatistiği \\
\hline LEV &,- 0239 &, 0054 & $\begin{array}{c}-4,035 \\
(, 000)^{* * *}\end{array}$ \\
\hline SIZE &, 4750 &, 4631 & $\begin{array}{c}945 \\
(, 345)\end{array}$ \\
\hline ROA & 8,1773 & 8,0044 & $\begin{array}{c}4,140 \\
(, 000)^{* * *}\end{array}$ \\
\hline
\end{tabular}

*, **, *** sirasıyla $\% 10, \% 5$ ve $\% 1$ düzeyinde anlamlılığı göstermektedir. 
Tablo 4'te dört büyük denetim firması tarafindan denetlenen işletmelerin tahakkuklarının ortalamas - 0,023 iken diğerleri tarafından denetlenen işletmelerin ortalaması 0,0054 olup iki grup arasında $\% 1$ anlamlılık düzeyinde önemli bir fark olduğu görülmektedir. Dört büyük denetim firması tarafından denetlenmeyen işletmelerin tahakkuklarının daha yüksek olması, söz konusu denetim firmaları tarafindan denetlenen işletmelerde, daha fazla kar yönetimi uygulaması olabileceği şeklinde değerlendirilebilir. Benzer şekilde ROA ve SIZE değişkenleri açısından dört büyük denetim firması ve diğerleri tarafından denetlenen işletmeler arasında \%1 düzeyinde istatistiksel olarak anlamlı bir fark olduğu belirlenmiştir. Bu sonuçlara göre dört büyük denetim firması tarafından denetlenen işletmelerin diğerleri tarafindan denetlenen işletmelere göre daha büyük ve daha karlı işletmeler olduğu söylenebilir. Bunun yanı sıra dört büyük denetim firması tarafından denetlenen işletmelerin borçlanma oranı (LEV) ile diğer denetim firmaları tarafindan denetlenen işletmelerin borçlanma oranı ortalamaları arasında önemli bir fark olmadığı görülmektedir.

Tablo 5 ve Tablo 6'da geliştirilen hipotezleri test etmek amaciyla yapılan regresyon analizi sonuçları yer almaktadır. Tablo 5'te MODEL I' e ait analiz sonuçları yer alırken, Tablo 6'da MODEL II' ye ait analiz sonuçları yer almaktadır.

Tablo 5. Regresyon Analizi Sonuçları-I

\begin{tabular}{|c|c|c|}
\hline BAĞIMSIZ DEĞİŞKEN & Katsayılar & $t$ istatistiğ $\mathbf{i}$ \\
\hline SABİT &,- 037 & $\begin{array}{l}-1,099 \\
(, 272)\end{array}$ \\
\hline BIG4 &,- 051 & $\begin{array}{c}-7,740 \\
(, 000) * * *\end{array}$ \\
\hline LEV & ,004 & $\begin{array}{c}, 286 \\
(, 775)\end{array}$ \\
\hline SIZE & ,003 & $\begin{array}{c}, 804 \\
(, 421)\end{array}$ \\
\hline ROA & ,675 & $\begin{array}{c}20,475 \\
(, 000) * * *\end{array}$ \\
\hline $\begin{array}{c}\text { Düz.R2 } \\
\text { Durbin- Watson } \\
\text { F Değeri }\end{array}$ & \multicolumn{2}{|c|}{$\begin{array}{c}, 240 \\
1,813 \\
\end{array}$} \\
\hline
\end{tabular}

Tablo sonuçları incelendiğinde kar yönetimi ile denetim kalitesi göstergesi olarak kullanılan BIG4 arasında negatif ve istatistiksel olarak anlamlı bir ilişkinin olduğu görülmektedir. Başka bir ifade ile dört büyük denetim firması tarafından denetlenen işletmelerin diğer denetim firmaları tarafından denetlenen işletmelere göre daha az kar yönetimi uyguladığı söylenebilir. Elde edilen bu sonuç H1 hipotezimizi desteklemekte ve literatür ile (Chen vd., 2005; Karacaer ve Özek, 2010; Gerayli vd., 2011; Zgarn vd., 2012; Comprix ve Huang,2015; Ahmadvd., 2016) tutarl1lık göstermektedir. 
Modele dahil edilen kontrol değişkenleri incelendiğinde ROA ile kar yönetimi arasında pozitif ve \%1 düzeyinde istatistiksel olarak anlamlı bir ilişki olduğu görülmektedir. ROA ve kar yönetimi arasındaki bu ilişkiyi karlılık düzeyleri yüksek olan işletmelerin kar yönetimi uygulamalarına daha eğilimli oldukları şeklinde yorumlamak mümkündür. Bunun yanında firma büyüklüğü (SIZE) ve borçlanma oranı (LEV) ile kar yönetimi arasında pozitif ancak istatistiksel olarak anlamlı olmayan bir sonuç elde edilmiştir.

Tablo 6. Regresyon Analizi Sonuçları-II

\begin{tabular}{|c|c|c|}
\hline BAĞIMSIZ DEĞIŞKEN & Katsayılar & t istatistiğ \\
\hline SABIT &,- 116 & $\begin{array}{c}, 814 \\
(, 417)\end{array}$ \\
\hline ÜCRET & 193 & $\begin{array}{c}, 436 \\
(, 664)\end{array}$ \\
\hline LEV & ,013 & $\begin{array}{c}, 242 \\
(, 809)\end{array}$ \\
\hline SIZE & ,013 & $\begin{array}{c}, 557 \\
(, 579)\end{array}$ \\
\hline ROA &, 547 & $\begin{array}{c}3,873 \\
(, 000)^{* * *}\end{array}$ \\
\hline $\begin{array}{c}\text { Düz.R2 } \\
\text { Durbin- Watson } \\
\text { F Değeri }\end{array}$ & & \\
\hline
\end{tabular}

Tablo 6'da MODEL II' ye ait regresyon analizi sonuçları incelendiğinde denetim kalitesi göstergesi olarak kullanılan denetim ücreti ile kar yönetimi arasında pozitif bir ilişki olduğu görülmektedir. Ancak bu pozitif ilişki istatistiksel olarak anlamlı değildir. Bu sonuç H2 hipotezimizin desteklenmediğini göstermektedir.

Kontrol değişkeni olarak kullanılan borçlanma oranı (LEV) ile firma büyüklüğü (SIZE) ile kar yönetimi arasında pozitif fakat istatistiksel olarak anlamlı olmayan bir ilişki olduğu belirlenmiştir. Son kontrol değişkeni olan ROA ile kar yönetimi arasında Tablo 4 'teki bulgularla tutarlı bir biçimde pozitif ve istatistiksel olarak anlamlı bir ilişki olduğu görülmektedir. Bu sonuç kar yönetiminin karlılık düzeyleri yüksek olan firmalarda daha fazla yapıldığını göstermektedir.

\section{SONUÇ VE DEĞERLENDİRME}

Yöneticiler ve hissedarlar arasında var olan bilgi asimetrisi yöneticilerin işletme ile ilgili bilgileri kendi çıkarları doğrultusunda kullanmasına neden olabilmektedir. $\mathrm{Bu}$ durum bağımsız dış denetime olan ihtiyacı artırmaktadır. Bağımsız dış denetim finansal tablolarda önemli yanlışlıkların bulunmadığına dair makul bir güvence sağlayan ve dolayısıyla hissedarların çıkarlarını koruyan bir izleme mekanizması olarak algılanmaktadır. Bu nedenle 
bağımsız dış denetim finansal raporlamanın şeffaflığını ve güvenilirliğini sağlamak için hissedarlar açısından önemli bir araçtır.

İşletme yönetimi tarafından yapılabilecek hataları, hileleri ve yolsuzlukları önlemek, denetçilerin bağımsızlığını güçlendirmek ve finansal raporlama kalitesini artırmak amacıyla denetim kalitesi gün geçtikçe daha da önem kazanmaktadır. Özellikle ABD'de ve bazı Avrupa ülkelerinde meydana gelen finansal skandalların temelinde yönetimin başarısızlığının yanı sıra kar yönetimi uygulamalarının olduğunun da düşünülmesi denetim kalitesinin sağlanması gerektiğini göstermiştir.

Ayrıca konuya ilişkin literatür incelendiğinde de yapılan teorik ve ampirik çalışmalarda kar yönetimi uygulamalarını sınırlandırma konusunda denetim kalitesinin önemli bir mekanizmaya sahip olduğu görülmektedir. Bu nedenle özellikle yatırımcıları kar yönetimi uygulamalarının olumsuzluklarından koruyabilmek amaciyla yapılan denetimlerin kaliteli olması büyük bir önem taşımaktadır.

Bu çalışmanın amacı denetim kalitesi ile kar yönetimi arasındaki ilişkiyi incelemektir. Bu amacı gerçekleştirmek üzere 2009-2015 yıllarını kapsayan ve Borsa İstanbul BİST 100 endeksinde işlem gören farklı sektörlere ait firmaların yıllık verilerinden 1525 adet veri kullanılmıştır.

Çalışmada denetim kalitesi göstergesi olarak literatür ile tutarlı bir biçimde denetim firması büyüklüğü (4 büyük denetim firması) ve denetim ücreti esas alınmıştır. Kar yönetimi göstergesi olarak ise literatür ile tutarlı bir biçimde isteğe bağlı tahakkuklar kullanılmış ve isteğe bağlı tahakkukların hesaplanmasında Modifiye Edilmiş Jones Modeli'nden yararlanılmıştır. Çalışmada ayrıca üç kontrol değişkeni (karlılık, kaldıraç ve büyüklük) kullanılmıştır.

Ampirik analizlerde regresyon analizinden yararlanılmıştır. Yapılan analiz sonucunda denetim kalitesi göstergesi olarak kullanılan denetim firması büyüklüğü ile kar yönetimi arasında negatif ve istatistiksel olarak anlamlı bir sonuç elde edilmiştir. Buna karşın denetim kalitesi göstergesi olarak kullanılan denetim ücreti ve kar yönetimi arasında pozitif ancak istatistiksel olarak anlamlı olmayan bir sonucun olduğu görülmektedir.

Literatür taraması kısmında özetlenen çalışmalardan da görüleceği üzere kar yönetimi ve denetim kalitesi arasındaki ilişkiyi incelemek üzere farklı ülkelerde çok sayıda çalışma olduğu görülmektedir. Konuya ilişkin Türkiye literatürü incelendiğinde sinırlı sayıda çalı̧̧manın (Karacaer ve Özek, 2010; Yaşar, 2011) olduğu belirlenmiştir. Söz konusu iki çalı̧̧mada da denetim kalitesi göstergesi olarak denetim firması büyüklügü̈ (4 büyük denetim firması) kullanılmıştır. Denetim kalitesi ve kar yönetimi arasındaki ilişkiyi Türkiye boyutu açısından inceleyen bu çalışmada söz konusu çalışmalardan farklı olarak denetim kalitesi göstergesi olarak denetim ücreti kullanılmıştır.

Güncel veriler kullanılarak ve örneklem hacmi geniş tutularak yapılan ve bu anlamda önemli olan bu çalışma bazı sınırlılıkları da kapsamaktadır. Denetim kalitesi göstergesi olarak bu çalışmada iki değişken kullanılmıştır. Ancak literatürde denetim kalitesi göstergesi olarak kullanılan değişkenler (denetçi endüstri uzmanlığı, denetim komitesi etkinliği, denetçi çalışma süresi gibi) veri eksikliği nedeniyle modele dahil edilmemiştir. Ayrıca denetim kalitesi 
göstergesi olarak denetim ücretinin kullanıldığı modelde örneklem hacmi düşüktür. Denetim ücreti ile ilgili gerekli verilere şirket mali tablolarından ulaşılamaması nedeni ile firmalar ile telefon ve e-posta yoluyla kurulan iletişim sonucunda yalnızca akademik amaçlı kullanılması ve şirket isimlerinin saklı tutulması koşuluyla yaklaşık 54 firmanın yalnızca 2014-2015 yıllarına ait denetim ücreti verilerine ulaşılabilmiştir. Sonuçların genelleştirilebilmesi için yeterli olan bu sayının artırılması daha sağlıklı sonuçların elde edilmesini sağlayabilir. Bunun yanı sıra çalışmada sektörel bir ayrım yapılmamıştır. Konuyla ilgili gelecekte yapılacak çalışmalarda bu hususlar dikkate alınabilir.

\section{KAYNAKLAR}

Abbasiazadeh, Laleh - Zamanpour, Alireza (2016), "Investigation The Effect of Audit Size on Earnings Management in Tehran Stock Exchange", International Journal of Humanities and Cultural Studies, https://www.ijhcs.com/index.php/ijhcs/article/.../2129, (17.11.2017).

Affes, Habib.- Smii, Tarak. (2016)," The Impact of The Audit Quality on that of The Earnings Management: Case Study in Tunisia", Journal of Accounting \&Marketing, 5(3), pp.18.

Ahmad, Lukman. - Suhara, Edi - Ilyas, Yusri (2016), “The Effect of Audit Quality on Earning Management within Manufacturing Companies Listed on Indonesian Stock Exchange", Research Journal of Finance and Accounting, 7(8), pp.132-138.

Alali, Fatima (2011), "Audit Fees and Discretionary Accruals: Compensation Structure Effect”, Managerial Auditing Journal, 26(2), pp.90-113.

Al-Quda, Laith Akram Muflih - Humeedat, Mohammed Mahmoud Ahmad - Al-Hroot, Yusuf Ali Khlaf (2017), "The Impact of Audit Firm Size and Auditor Tenure in the Reduction of Earnings Management (An Empirical Study on Industrial Corporations Listed on Amman Stock Exchange)", Journal of Administrative and Economics Science, 10(2), pp.151-186.

Antle, Rick - Gordon, Elizabeth - Narayanamoorthy, Ganapathi - Zhou, Ling (2006), "The Joint Determination of Audit Fees, Non-Audit Fees, and Abnormal Accruals", Review of Quantitative Finance and Accounting, 27(2006), pp. 235-266.

Bamahros, Hasan Mohammed - Wan-Hussin, Wan Nordin (2015), "Non-Audit Services, Audit Firm Tenure and Earnings Management In Malaysia", Asian Academy of Management Journal Of Accounting and Finance, 11(1), pp.145-168.

Bauwhede, Heidi Vander - Willekens, Marleen - Gaeremynck, Ann (2003), “Audit Firm Size, Public Ownership, and Firms' Discretionary Accruals Management", The International Journal of Accounting, 38(1), pp.1-22.

Becker, Connie L - Defond, Mark L. - Jiambalvo, James - Subramanyam, K.R. (1998), "The Effect of Audit Quality on Earnings Management", Contemporary Accounting Research, 15(1), pp.1-24. 
Cai, C., Zhao, S. - Huang, Y. (2005), "Toward The Effect of Audit Quality on Earnings Management-Empirical Evidence From Manufacturing Enterprises Listed in Shangai Stock Market", Journal of Modern Accounting and Auditing, 1(2), pp.69-80.

Caramanis, Constantinos - Lennox, Clive (2008), "Audit Effort and Earnings Management", Journal of Accounting and Economics, 45(1), pp.116-138.

Chen, Hanwen - Chen, Jeff Zeyun - Lobo, Gerald J. - Wang, Yanyan (2011), "Effects of Audit Quality on Earnings Management and Cost of Equity Capital: Evidence from China", Contemporary Accounting Research, 28(3), pp. 892-925.

Chen, Ken Y. - Lin, Kuen-Lin - Zhou, Jian (2005),” Audit Quality and Earnings Management for Taiwan IPO Firms", Managerial Auditing Journal, 20(1), pp.86-104.

Chen, Ken.Y. - Wu, Shang-Ying. - Zhou, Jian (2006), "Auditor Brand Name, Industry Specialisation and Earnings Management: Evidence From Taiwanese Companies", International Journal of Accounting Auditing and Performance Evaluation, 3(2), pp.194-219.

Chen, Xiaolin - Kong, Dongmin - Wang, Yutao. (2014), "Audit Firm Size, Earnings Management and Information Asymmetry", China Accounting and Finance Review, 16(1), pp.29-60.

Comprix, Joseph - Huang, Huichi (2015), "Does Auditor Size Matter? Evidence From Small Audit Firms", Advances in Accounting, 31(1), pp.11-20.

DeAngelo, Linda Elizabeth (1981), “Auditor Size and Audit Quality”, Journal of Accounting and Economics, 3(3), pp.183-199.

Dechow, Patricia M. - Sloan, Richard G. - Sweeney, Amy P. (1995), "Detecting Earnings Management". The Accounting Review, 70 (2), pp.193-225.

Elder, Randal J. - Zhou, Jian (2002), “Audit Firm Size, Industry Specialization and Earnings Management by Initial Public Offering Firms", Working Paper, , https://papers.ssrn.com/sol3/papers.cfm?abstract_id=321041. (Erişim Tarihi, 25 Ağustos 2017)

Frankel, Richard M. - Johnson, Marilyn F. - Nelson, Karen K. (2002), “The Relation Between Auditors' Fees for Non-Audit Services and Earnings Management", The Accounting Review (Supplement), pp.71-105.

Gerayli, Mahdi Safari - Yanesari, Abolfazl Momeni - Ma'atoofi, Ali Reza (2011), "Impact of Audit Quality on Earnings Management: Evidence From Iran", International Research Journal of Finance and Economics, No: 66, pp.77-84.

Greiner, Adam - Kohlbeck, Mark - Smith, Thomas (2013), "Do Auditors Perceive Real Earnings Management as a Business Risk?”, http://dx.doi.org/10.2139/ssrn.2239959 (25.05.2017) 
Gu, Junjian. - Hu, S.D. (2015), “Audit Fees, Earnings Management, and Litigation Risk: Evidence From Japanese Firms Cross-Listed on U.S. Markets", Academy of Accounting and Financial Studies Journal, 19(3), pp.125-139.

Gumanti, Tatang Ary - Nastiti, Ari Sita - Utami, Elok Sri - Manik, Ester (2015), “Audit Quality and Earnings Management In Indonesian Initial Public Offerings", Mediterranean Journal of Social Sciences MCSER Publishing, Rome-Italy, 6(5), pp.223-229.

Hay, David C. - Knechel, W. Robert - Wong, Norman (2006), “Audit Fees: A Meta-analysis of The Effect of Supply and Demand Attribute", Contemporary Accounting Research, 23(1), pp.141-191.

Jeong, Seok Woo - Rho, Joonhwa (2004), "Big Six Auditors and Audit Quality: The Korean Evidence", The International Journal of Accounting, No:39, pp.175- 196.

Jeong, SeokWoo - Rho, Joonhwa (2004), "Big Six Auditors and Audit Quality: The Korean Evidence", The International Journal of Accounting, 39, pp.175- 196.

Jones, Jennifer J. (1991), "Earnings Management During Import Relief Investigations", Journal of Accounting Research, 29(2), pp.193-228.

Kanagaretnam, Kiridaran - Lim, Chee Yeow - Lobo, Gerald J. (2010), "Auditor Reputation and Earnings Management: International Evidence From The Banking Industry", Journal of Banking \& Finance, No:34, pp.2318-2327.

Karacaer, Semra - Özek, Pelin (2010). "Denetim Firmasının Büyüklüğü ve Kâr Yönetimi İlişkisi: İMKB Şirketleri Üzerinde Ampirik Bir Araştırma", Muhasebe ve Finansman Dergisi, No:48, pp.60-74.

Kramer, Stefan Thomas - Georgakopoulos, Georgios - Sotiropoulo, Ioannis - Vasileiou, Konstantinos Z. (2011) "Audit Firm Rotation, Audit Firm Tenure and Earnings Conservatism", International Journal of Business and Management, 6(8), pp.44-57.

Li, June. - Lin, Jerry.W. (2005), “The Relation Between Earnings Management and Audit Quality", Journal of Accounting and Finance Research, 12(1),pp. 1-11.

Martinez, Antonio Lopo - Reis, Graciela Mendes Ribeiro (2010), “Audit Firm Rotation and Earnings Management in Brazil", Working Paper, https://papers.ssrn.com/sol3/papers.cfm?abstract_id=1640260 (24.08.2017)

Martinez, Antonio Lopo - Moraes, Arquimedes De Jesus (2017), "Relationship Between Auditors' Fees And Earnings Management", Revista de Administração de Empresas, 57(2),http://www.scielo.br/scielo.php?pid=S0034-

75902017000200148\&script=sci_arttext (9.11.2017)

Memiş, Mehmet Ünsal - Çetenak, Emin Hüseyin (2012), "Earnings Management, Audit Quality and Legal Environment: An International Comparison", International Journal of Economics and Financial Issues, 2(4),pp. 460-469. 
Memiş, Mehmet Ünsal - Çetenak, Emin Hüseyin (2012), "Kurumsal Yönetimin Kazanç Yönetimi Uygulamaları Üzerine Etkisi: İmkb'de İşlem Gören Şirketler Üzerine Uygulama", Çukurova Üniversitesi Sosyal Bilimler Enstitüsü Dergisi, 3(21), ss.205224.

Namazi, Mohammad - Bayazidi, Anvar - Jabbarzadeh, Kangarluei Saeed (2011), "Determining The Relationship Between Auditing Quality And Earnings Management For Listed Companies in the Tehran Securily Exchange", Accounting Research, 3(9), pp.4-21.

Nawaiseh, Mohammad Ebrahim (2016), "Can Earnings Management be Influenced by Audit Quality?" International Journal of Finance and Accounting, 5(4), pp.209-219.

Nicolaescu, Eugen (2014), “The Effect of Audit Firm Rotation on Earnings Quality?", Economics, Management and Financial Market, 9(1), pp.148-153. https://www.questia.com/library/journal/1P3-3289824551/the-effects-of-audit-firmrotation-on-earnings-quality (24.08.2017,)

Okolie, Augustine O. (2014), "Auditor Tenure, Auditor Independence And Accrual - Based Earnings Management of Quoted Companies In Nigeria", European Journal of Accounting Auditing and Finance Research, 2(2), pp.63-90.

Palmrose, Zoe Vonna (1986)i "Audit Fees and Auditor Size: Further Evidence". Journal of Accounting Research, 24(1), pp.97-110.

Pouraghajan, Abbasali - Tabari, Naser Ali Yadollahzadeh - Emamgholipour, Milad Mansourinia, Elham (2013), "The Effect of Audit Quality on Earnings Management: Evidence from Iran", International Journal of Basic Sciences \& Applied Research, 2(4), pp.399-404.

Rusmin, Rusmin (2010), "Auditor Quality and Earnings Management: Singaporean Evidence", Managerial Auditing Journal, 25(7), pp.618-638.

Schelleman, Caren. - Knechel, W. Robert (2010), "Short-Term Accruals and The Pricing and Production of Audit Services", Auditing: A Journal of Practice \& Theory, 29(1), pp.221-250.

Schipper, Katherine (1989), "Commentary On Earnings Management”, Accounting Horizons, 3(4), pp.91-102.

Simunic, Dan A. (1980), "The Pricing of Audit Services: Theory and Evidence", Journal of Accounting Research, 18(1), pp.161-190.

Tendeloo, Brenda Van - Vanstraelen, Ann (2008), "Earnings Management and Audit Quality in Europe: Evidence from the Private Client Segment Market", European Accounting Review, Vol. 17, No. 3, pp.447-469. 
Yaşar, Alpaslan (2011), "Bağımsız Dış Denetim Kalitesinin Kar Yönetimi Üzerine Etkisi: İmkb'de Kayıtlı İşletmeler Üzerine Bir Uygulama”, Yayınlanmamış Doktora Tezi. Adana: ÇÜ. Sosyal Bilimler Enstitüsü.

Zgarni, Inaam - Hlioui, Khmoussi - Zehri, Fatma (2012), “Audit Quality and Earnings Management in theTunisian Context", International Journal of Accounting and Financial Reporting, 2(2), pp.17-33.

Zhou, Jian - Elder, Randal (2001), “Audit Firm Size, Industry Specialization and Earnings Management by Initial Public Offering Firms", https://www.researchgate.net/publication/228307612 (21.05.2017)

Zuo, Lingyan - Guan, Xiaomeng (2014), "The Association of Audit Firm Size and Industry Specialization on Earnings Management: Evidence in China", The Macrotheme Review, 3(7), pp.1-21. 
